\title{
Ethnicity and socioeconomic status are related to dietary patterns at age 5 in the Amsterdam born children and their development $(A B C D)$ cohort
}

Viyan Rashid ${ }^{1 *}$, Marielle F. Engberink' ${ }^{1}$, Manon van Eijsden², Mary Nicolaou ${ }^{3}$, Louise H. Dekker ${ }^{3}$, Arnoud P. Verhoeff ${ }^{2,4}$ and Peter J. M. Weijs ${ }^{1,5}$

\begin{abstract}
Background: Health inequalities are already present at young age and tend to vary with ethnicity and socioeconomic status (SES). Diet is a major determinant of overweight, and studying dietary patterns as a whole in relation to overweight rather than single nutrients or foods has been suggested. We derived dietary patterns at age 5 and determined whether ethnicity and SES were both related to these dietary patterns.

Methods: We analysed 2769 validated Food Frequency Questionnaires filled in by mothers of children $(5.7 \pm 0.5 y)$ in the Amsterdam Born Children and their Development $(A B C D)$ cohort. Food items were reduced to 41 food groups. Energy adjusted intake per food group $(\mathrm{g} / \mathrm{d})$ was used to derive dietary patterns using Principal Component Analysis and children were given a pattern score for each dietary pattern. We defined 5 ethnic groups (Dutch, Surinamese, Turkish, Moroccan, other ethnicities) and 3 SES groups (low, middle, high, based on maternal education). Multivariate ANOVA, with adjustment for age, gender and maternal age, was used to test potential associations between ethnicity or SES and dietary pattern scores. Post-hoc analyses with Bonferroni adjustment were used to examine differences between groups.

Results: Principal Component Analysis identified 4 dietary patterns: a snacking, full-fat, meat and healthy dietary pattern, explaining $21 \%$ of the variation in dietary intake. Ethnicity was related to the dietary pattern scores $(p<0.01)$ : non-Dutch children scored high on snacking and healthy pattern, whereas Turkish children scored high on full-fat and Surinamese children on the meat pattern. SES was related to the snacking, full-fat and meat patterns $(p<0.01)$ : low SES children scored high on the snacking and meat pattern and low on the full-fat pattern.
\end{abstract}

Conclusions: This study indicates that both ethnicity and SES are relevant for dietary patterns at age 5 and may enable more specific nutrition education to specific ethnic and low socioeconomic status target groups.

Keywords: Dietary patterns, PCA, Children, Preschool children, Ethnicity, Socioeconomic status, Overweight

\footnotetext{
* Correspondence: v.rashid@hva.nl

${ }^{1}$ Department of Nutrition and Dietetics, Faculty of Sports and Nutrition,

Amsterdam University of Applied Sciences, Dr. Meurerlaan 8, 1067, SM,

Amsterdam, The Netherlands

Full list of author information is available at the end of the article
}

(c) The Author(s). 2018 Open Access This article is distributed under the terms of the Creative Commons Attribution 4.0 International License (http://creativecommons.org/licenses/by/4.0/), which permits unrestricted use, distribution, and reproduction in any medium, provided you give appropriate credit to the original author(s) and the source, provide a link to the Creative Commons license, and indicate if changes were made. The Creative Commons Public Domain Dedication waiver (http://creativecommons.org/publicdomain/zero/1.0/) applies to the data made available in this article, unless otherwise stated. 


\section{Background}

Health inequalities, such as the prevalence of overweight, are already present at a young age and tend to vary on the basis of ethnicity and socioeconomic (SES) status [1-3]. Diet is a major determinant of overweight [4-6], and studying dietary patterns as a whole in relation to overweight rather than single nutrients or foods has been suggested [7-9].

Dietary patterns are population specific and influenced by sociocultural factors and food availability [10, 11]. In recent decades, European populations have become increasingly ethnically diverse and ethnic minority groups are often disproportionate in lower SES groups [12]. The predominant ethnic minority groups, i.e. Turkish, Arabs (North African and Middle Eastern), Berbers and Black Africans (Afro-Caribbean and others by descent), form approximately 3\% of the total European population, with the largest numbers in Western European countries [13]. Non-native groups have less often completed higher education than native borns [14] which makes observation of SES differences also of interest.

Socioeconomic differences in dietary patterns have been described in adults. In children, SES differences in dietary patterns has been observed in several studies including 4 prospective birth cohorts in 3 countries in Europe, i.e. The Avon Longitudinal Study of Parents and Children (ALSPAC) cohort, the EDEN mother-child cohort, the Norwegian Mother and Child Cohort Study and the Southampton Women's Cohort Survey [15-23]. Data on ethnic differences in dietary patterns among children is limited [24]. To our knowledge, only the ALSPAC cohort identified an association between ethnicity dividing the study population into white and nonwhite ethnicity $[18,19]$. However, the diversity of ethnic groups in Western Europe is more pronounced and we expect to observe differences in dietary intake between ethnic groups [25-27]. Exploring the potential ethnic diversity as well as socioeconomic differences in dietary patterns in children may provide new and more specific insight for public healthcare professionals to identify groups with poor dietary habits.

Therefore, the aim of the present study was to derive dietary patterns at age 5 in the multi-ethnic Amsterdam Born Children and their Development (ABCD) cohort and to examine potential associations with either or both ethnicity and SES.

\section{Methods}

Study design and study population

Data were used from the ABCD study, a large ongoing community-based birth cohort (http://www.abcdstudy.nl/). The cohort study design has been described previously [28]. Figure 1 shows the study procedure and inclusion in the current analysis. In brief, between January 2003 and March 2004, all pregnant women living in Amsterdam were invited to participate in the ABCD

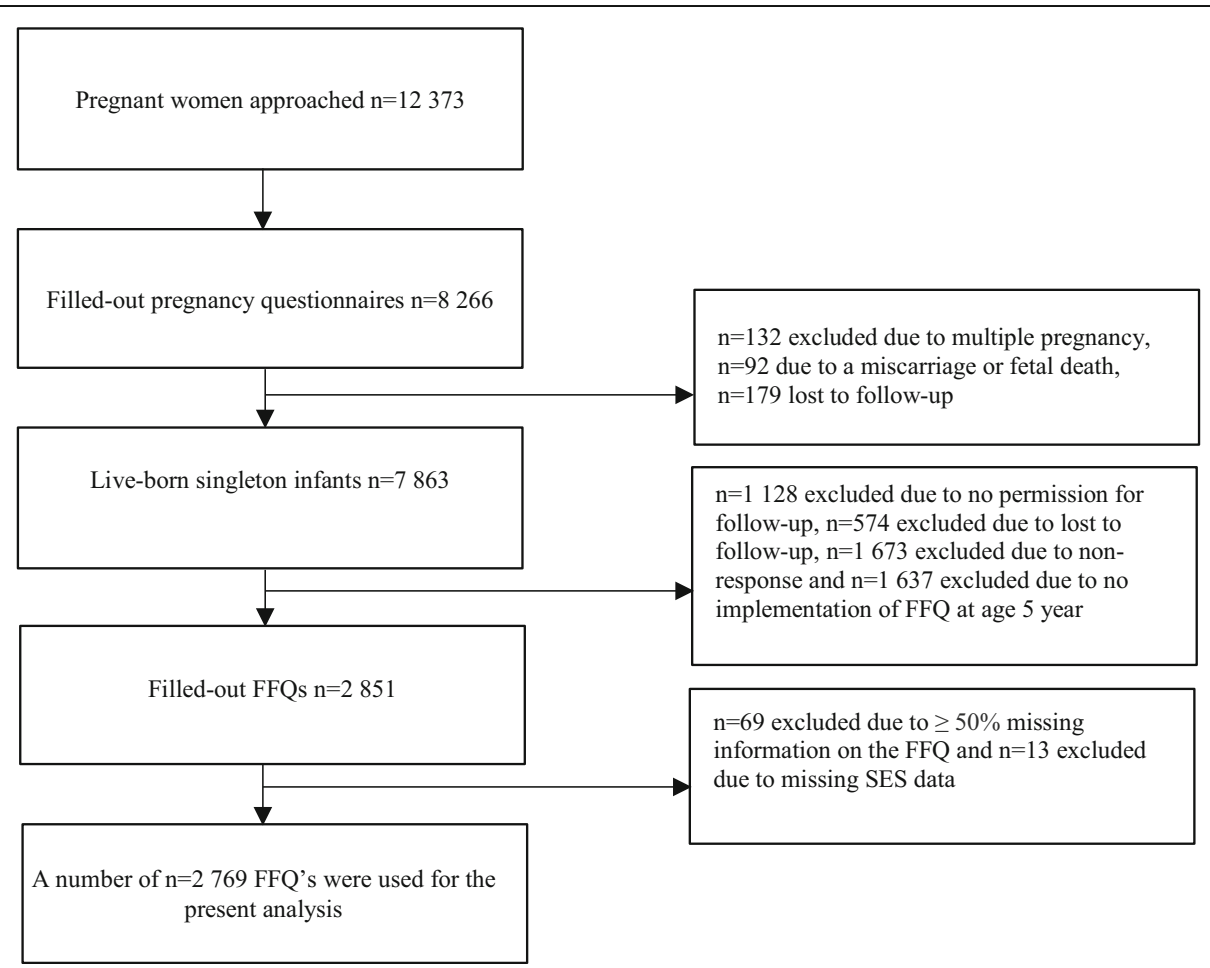

Fig. 1 Flowchart of the inclusion into the present analysis $(n=2769)$ 
study by their obstetric care provider at their first prenatal care visit. Of the 12,373 women approached, 8266 women filled out a pregnancy questionnaire that covered socio-demographic characteristics, obstetric history, family history and lifestyle, which was available in Dutch, English, Turkish and the Arabic language. When the children turned 5 years of age, 4488 received a selfadministered Food Frequency Questionnaire (FFQ) by post and a number of 2851 mothers returned the FFQ. Based on a data clearance protocol set by TNO Food (Zeist, The Netherlands), children were excluded from analysis with more than $50 \%$ missing per page or per cluster of food items $(n=69)$. Finally, 13 children were excluded as years of education of the mother was not available in the pregnancy questionnaire, resulting in 2769 children included in the present analysis.

Efforts to enhance participation among all women and children, regardless of ethnicity and education were done by using translated questionnaires and information leaflets. Also, women from ethnic minority groups who did not respond within a month were approached by phone by trained students who explained the study in the women's preferred language. Attrition in follow-up number was largely attributable to untraceable changes in address or migration. This study was approved by the institutional review committee of the Academic Medical Center, and the Registration Committee of Amsterdam. All of the participants gave written informed consent for themselves and their children. The present study was conducted according to the guidelines laid down in the Declaration of Helsinki.

\section{Dietary assessment}

A validated 71-item FFQ, developed by TNO Food (Zeist, The Netherlands) was used [29]. Per food item, consumption frequency, portion size and the type of product consumed over the last 4 weeks was reported by the mother of the child. Frequency options were "never", "less than once a week", "once a week", "2-3 times a week", "4-5 times a week", and "6-7 times a week". Food items were assessed in units (e.g. a piece of fruit and a slice of bread) and in household units (e.g. a glass and a tablespoon). Intake of items such as breakfast cereals, vegetables or pasta were asked in standard tablespoons which could give a reliable idea of the actual eaten portion size for children. Based on the data clearance protocol developed by TNO Food, the returned FFQs were scanned and the data were checked for inconsistencies or extreme values. Impossible values were defined as portion sizes larger than the maximum portion size consumed in the Dutch Food Consumption Survey and were imputed by the mean. For example a maximum of 6 tablespoons of cooked vegetables (180 g) per day was substituted when a higher amount was filled in. Frequencies and portion sizes were converted into weights (g/day) of product consumed and intake of energy was calculated using the Dutch Food Composition Database (NEVO) 2010 [30]. Each food item in the questionnaire was linked with one or more foods from the Dutch Food Composition Database. In total, a number of 308 different NEVO codes were used for analysis. After calculation of the scanned FFQs, inconsistencies in energy intake for those children with the $5 \%$ highest and $5 \%$ lowest intake of energy were checked with the original FFQ. When the FFQ was filled in correctly, FFQ's of these children were not excluded as we expect that these high or low energy intakes might reflect a realistic intake.

\section{Assessment of ethnicity and socioeconomic status}

Data on ethnicity and SES was collected via the pregnancy questionnaire, filled out by the mother during the baseline measurements of the ABCD study. Five ethnic categories were formed: Dutch, Surinamese, Turkish, Moroccan and other ethnicities (mainly non-western origin). We excluded the Surinamese South Asians because of specific body composition and cardiometabolic risk [31]. Ethnicity was based on the country of birth of the pregnant woman and her mother including both first-generation women (born outside the Netherlands) and second generation women (born in the Netherlands but whose mother was born in another country). When the pregnant woman or her mother were born in a country defined as 'none of the given options': the participant's self-registered ethnic origin was used [32].

The pregnant women's education after primary school was defined in years and considered as a proxy for SES. Low SES was defined as a maximum of 5 years postprimary education, middle SES as 6-10 years and high SES was defined as more than 10 years of post-primary education [33].

\section{Assessment of dietary patterns}

Principal Component Analyses (PCA) with varimax rotation was used to derive dietary patterns. Food items, including different type of products, were reduced to 41 food groups, based on nutritional value and culinary use. The list with food groups and its type of products can be found in Additional file 1. Products such as ginger cake and raisins are often given to children as a healthy alternative for biscuits or candy and were therefore assigned to the food group "healthy snacks". Because we were interested in the effect of dietary quality independent of its energy content, we adjusted total energy intake using the nutrient residual method [34, 35]. Standardized energy adjusted intake ( $\mathrm{g} / \mathrm{d})$ of the 41 food groups were used in the PCA analysis. The number of components (dietary patterns) retained was based on the scree 
plot [see Additional file 2], eigenvalues $>1$ and the interpretability of the dietary patterns $[36,37]$. Food groups with component loadings $\geq 0.3$ were considered important for interpretability of the dietary patterns. A larger absolute factor loading indicates a higher positive or negative correlation between the food group and a given dietary pattern. The patterns were named after the nature of the food groups with the highest component loadings within each pattern.

Individuals were given a pattern score for each pattern as a sum of the 41 standardized food group intakes, each weighted according to their factor loading. Positive pattern scores indicate higher consumption of food groups in that pattern.

\section{Statistical analysis}

Statistical analyses were performed in SPSS version 22 for windows. Population characteristics were described in percentages or means with standard deviations (SD), shown for the total population and by ethnicity. Univariate and multivariate ANOVA was used to determine whether ethnicity and/or SES were related to dietary patterns with the individual pattern score of each dietary pattern used as continuous dependent variable and ethnicity or SES used as independent variables (Model 1; crude). The association with ethnicity was additionally adjusted for SES (dummy) and the association with SES was additionally adjusted for ethnicity (dummy) (Model 2). In the fully adjusted model (Model 3) the association with ethnicity was adjusted for child's age (y), gender, maternal age (y) and SES (dummy) and the analysis with SES was adjusted for age (y), gender, maternal age (y) and ethnicity (dummy). Mean \pm SE pattern scores were shown for each of the dietary patterns by ethnic and SES group separately. Post-hoc analyses with Bonferroni adjustment was used to examine differences between groups. Additionally, we tested for interaction by SES in the association between ethnicity and dietary pattern scores. $P<0.01$ was considered significant.

\section{Results}

\section{Population characteristics}

Characteristics of the study population, divided by ethnicity are shown in Table 1 . Mean age of the study population was $5.7 \pm 0.5$ years and $51 \%$ of the population was boy. The percentage of children from Dutch origin was $82.4 \%$, followed by Surinamese (4.2\%), Moroccan (4.1\%), Turkish (2.2\%) and other ethnicities (7.1\%). The majority of children (53.3\%) belonged to the high SES, $35.4 \%$ to middle SES and $11.3 \%$ to low SES group.

\section{Dietary patterns}

PCA identified 4 dietary patterns in this cohort explaining $20.8 \%$ of the variation of dietary intake, according to the Rotated Sums of Squared Loadings. In Table 2, an overview of the component loadings from $\geq 0.3$ is shown per dietary pattern. The snacking pattern was mainly characterized by high intakes of savoury snacks and refined breakfast products and low intakes of whole-grain breakfast products. The full-fat pattern was characterized by high intakes of full-fat spreads and pasta dishes and low intakes of low-fat spreads. The meat pattern was characterised by high intakes of low- and high-fat meat, sauces and refined grain products for warm meals. Finally the healthy pattern was characterised by high intakes on the food groups water and tea, vegetables, fish and fruits.

\section{Ethnicity and dietary patterns}

Ethnicity was significantly related to dietary pattern scores $(p<0.01$, Table 3$)$. Post-hoc analyses showed that Dutch children had significantly lower $(-0.171 \pm 0.019$, $p<0.01)$ snacking scores compared to the other ethnic groups, whereas Turkish children had significantly higher $(1.363 \pm 0.118, p<0.01)$ snacking scores. After adjustment for SES the associations were less pronounced $(-0.124 \pm 0.019$ for Dutch, $0.998 \pm 0.117$ for Turkish), but still significant for most groups. Further adjustment for age, gender and maternal age did not change the results (Table 3). With respect to the full-fat pattern,

Table 1 Population characteristics in the ABCD cohort by ethnicity $(n=2769)$

\begin{tabular}{|c|c|c|c|c|c|c|}
\hline Population characteristics & $\begin{array}{l}\text { Total population } \\
(n=2769)\end{array}$ & $\begin{array}{l}\text { Dutch } \\
(n=2283,82.4 \%)\end{array}$ & $\begin{array}{l}\text { Surinamese } \\
(n=116,4.2 \%)\end{array}$ & $\begin{array}{l}\text { Moroccan } \\
(n=112,4.1 \%)\end{array}$ & $\begin{array}{l}\text { Turkish } \\
(n=61,2.2 \%)\end{array}$ & $\begin{array}{l}\text { Other ethnicities } \\
(n=197,7.1 \%)\end{array}$ \\
\hline Age, in year (Mean, SD) & $5.7,0.5$ & $5.7,0.5$ & $5.8,0.5$ & $6.0,0.6$ & $5.9,0.5$ & $5.7,0.5$ \\
\hline Boy, $n(\%)$ & $1415(51.1)$ & $1166(51.1)$ & $58(50.0)$ & $64(57.1)$ & $34(55.7)$ & $93(47.2)$ \\
\hline \multicolumn{7}{|l|}{ Socioeconomic status, n (\%) } \\
\hline Low & $313(11.3)$ & $145(6.4)$ & $38(32.8)$ & $48(42.9)$ & $33(54.1)$ & $49(24.9)$ \\
\hline Middle & $980(35.4)$ & $759(33.2)$ & $57(49.1)$ & $55(49.1)$ & $25(41.0)$ & $84(42.6)$ \\
\hline High & $1476(53.3)$ & $1379(60.4)$ & $21(18.1)$ & $9 .(8.0)$ & $3(4.9)$ & $64(32.5)$ \\
\hline Maternal age (Mean, SD) & $32.3,4.3$ & $32.8,3.8$ & $30.6,5.8$ & $27.9,4.9$ & $27.1,6.0$ & $31.5,4.8$ \\
\hline
\end{tabular}

Ethnicity was based on the country of birth of the pregnant woman and her mother including both first-generation women and second generation women. SES was based on maternal educational: low SES $(\leq 6 \mathrm{y})$, middle SES (6-10y) and high SES ( $\geq 10 \mathrm{y})$ post-primary education. 
Table 2 Component loadings $(\geq 0.3$ ) of the 41 food groups per dietary pattern

\begin{tabular}{|c|c|c|c|c|}
\hline & \multicolumn{4}{|c|}{ Dietary patterns } \\
\hline & Snacking & Full-fat & Meat & Healthy \\
\hline Explained variance (\%) & 7.1 & 4.6 & 4.6 & 4.4 \\
\hline Savory snacks & 0.47 & - & - & - \\
\hline Refined breakfast products & 0.45 & - & - & - \\
\hline Ice cream & 0.42 & - & - & - \\
\hline Sauces & 0.41 & - & 0.35 & - \\
\hline Choclate and candy & 0.38 & - & - & - \\
\hline Fruit drink & 0.31 & - & - & - \\
\hline Full-fat dairy & 0.30 & - & - & - \\
\hline Low-fat spreads & -0.38 & -0.55 & - & - \\
\hline Sandwich toppings (sweet) & -0.38 & - & - & -0.33 \\
\hline Whole grain breakfast products & -0.74 & - & - & - \\
\hline Tomato sauce for pasta & - & 0.61 & - & - \\
\hline Full-fat spreads & - & 0.48 & -0.30 & - \\
\hline Refined grain products warm meal & - & 0.46 & 0.34 & - \\
\hline Full-fat cheese & - & 0.37 & - & - \\
\hline Low-fat cheese & - & -0.35 & - & - \\
\hline Low-fat meat & - & - & 0.44 & - \\
\hline High-fat meat & - & - & 0.39 & - \\
\hline Healthy meals & - & - & 0.31 & - \\
\hline Boiled potatoes & - & - & 0.30 & - \\
\hline Unhealthy meals & - & - & -0.32 & - \\
\hline Peanut butter & - & - & -0.34 & - \\
\hline Water and tea & - & - & - & 0.48 \\
\hline Vegetables & - & - & - & 0.47 \\
\hline Fish & - & - & - & 0.46 \\
\hline Fruits & - & - & - & 0.38 \\
\hline Whole grain products warm meal & - & - & - & 0.36 \\
\hline Nuts & - & - & - & 0.31 \\
\hline Pulses & - & - & - & 0.30 \\
\hline Artificially sweeted sodas & - & - & - & - \\
\hline Biscuits and pastries & - & - & - & - \\
\hline Egg & - & - & - & - \\
\hline Fried potato products & - & - & - & - \\
\hline Fruit drink concentrate & - & - & - & - \\
\hline Granola bars & - & - & - & - \\
\hline Healthy snacks & - & - & - & - \\
\hline Low-fat dairy & - & - & - & - \\
\hline Meat alternatives and soy products & - & - & - & - \\
\hline Medium-fat dairy & - & - & - & - \\
\hline Processed meats & - & - & - & - \\
\hline Sugar & - & - & - & - \\
\hline
\end{tabular}

Table 2 Component loadings ( $\geq 0.3$ ) of the 41 food groups per dietary pattern (Continued)

\begin{tabular}{|c|c|c|c|c|}
\hline & \multicolumn{4}{|c|}{ Dietary patterns } \\
\hline & Snacking & Full-fat & Meat & Healthy \\
\hline Sugar sweeted sodas & - & - & - & - \\
\hline \multicolumn{5}{|c|}{ a. Rotation converged in 12 iterations } \\
\hline
\end{tabular}

Turkish children and children from other ethnicities had higher pattern scores compared to Moroccan children $(0.283 \pm 0.128$ and $0.167 \pm 0.071$ versus $-0.247 \pm 0.094, p$ $<0.01$ ), whereas Surinamese children scored higher on the meat pattern $(0.589 \pm 0.092)$ compared to the other ethnic groups $(\mathrm{p}<0.01)$. Adjustment for SES did somewhat diminish the associations, but not the level of significance (Table 3). Further adjustment for other confounding factors yielded similar results (Table 3). The healthy pattern was most pronounced within the groups of Turkish and Moroccan children $(0.660 \pm 0.092$ for Moroccan and $0.602 \pm 0.125$ for Turkish, $p<0.01$ ). Adjustment for SES and other factors did not change the results.

\section{Socioeconomic status and dietary patterns}

SES was significantly related to snacking, full-fat and meat dietary pattern scores $(p<0.01$, Table 4$)$. Post-hoc analyses showed that low SES children had significantly higher snacking pattern scores $(0.864 \pm 0.052)$ compared to middle $(0.171 \pm 0.030)$ and high SES groups $(-0.297 \pm$ $0.024, p<0.01$ ). After adjustment for ethnicity the associations were less pronounced $(0.590 \pm 0.054$ for low SES, $0.137 \pm 0.029$ for middle SES and $-0.216 \pm 0.024$ for high SES), but still significant. Further adjustment for age, gender and maternal age did not change the results. The full-fat pattern was most pronounced within the group of high SES children $(0.055 \pm 0.026, p<0.01)$. The meat pattern was most pronounced in low SES children $(0.229 \pm 0.056, p<0.01)$. After adjustment for ethnicity, associations were more pronounced (Table 4). Further adjustment for age, gender and maternal age did not change the results (Table 4). SES was significantly related to the healthy pattern in the crude model $(p<0.01$, Table 4) showing low SES children had higher healthy pattern scores $(0.217 \pm 0.056)$ compared to middle $(0.004 \pm 0.032)$ and high SES children $(-0.049 \pm 0.026)$. After adjustments in either model 2 or 3 , SES was no longer significantly associated with the healthy pattern.

\section{Ethnicity, socioeconomic status and dietary patterns}

The main positive significant associations between ethnicity, SES and dietary patterns in the fully adjusted model are shown in Fig. 2. We tested for interaction between 
Table 3 Mean dietary pattern scores by ethnicity in the ABCD cohort $(n=2769)$

\begin{tabular}{|c|c|c|c|c|c|c|c|c|c|c|c|}
\hline \multirow[t]{2}{*}{ Dietary pattern } & \multicolumn{2}{|l|}{ Dutch } & \multicolumn{2}{|c|}{ Surinamese } & \multicolumn{2}{|l|}{ Turkish } & \multicolumn{2}{|c|}{ Moroccan } & \multicolumn{2}{|c|}{ other ethnicities } & \multirow{2}{*}{$\begin{array}{l}P \text { value } \\
\text { ANOVA }\end{array}$} \\
\hline & Mean & SE & Mean & SE & Mean & SE & Mean & SE & Mean & SE & \\
\hline \multicolumn{12}{|l|}{ Snacking } \\
\hline Model 1: Crude & -0.171 & $0.019^{a}$ & 0.797 & $0.086^{\mathrm{b}, \mathrm{d}}$ & 1.363 & $0.118^{\mathrm{a}}$ & 0.819 & $0.087^{b, d}$ & 0.626 & $0.066^{b, d}$ & $<0.01$ \\
\hline Model 2: SES & -0.124 & $0.019^{\mathrm{a}}$ & 0.576 & $0.084^{\mathrm{b}}$ & 0.998 & $0.117^{b, e, f}$ & 0.516 & $0.087^{\mathrm{b}, \mathrm{d}}$ & 0.491 & $0.064^{b, d}$ & $<0.01$ \\
\hline Model 3: Fully adjusted & -0.122 & $0.019^{\mathrm{a}}$ & 0.567 & $0.084^{b}$ & 0.987 & $0.119^{b, e, f}$ & 0.505 & $0.089^{b, d}$ & 0.485 & $0.064^{\mathrm{b}, \mathrm{d}}$ & $<0.01$ \\
\hline \multicolumn{12}{|l|}{ Full-fat } \\
\hline Model 1: Crude & -0.003 & 0.021 & -0.127 & 0.093 & 0.283 & $0.128^{e}$ & -0.247 & $0.094^{\mathrm{d}, \mathrm{f}}$ & 0.167 & $0.071^{e}$ & $<0.01$ \\
\hline Model 2: SES & -0.019 & 0.021 & -0.054 & 0.094 & 0.409 & $0.131^{\mathrm{e}}$ & -0.146 & $0.097^{d}$ & 0.212 & 0.072 & $<0.01$ \\
\hline Model 3: Fully adjusted & -0.021 & $0.021^{d}$ & -0.054 & 0.094 & 0.433 & $0.132^{\mathrm{b}, \mathrm{e}}$ & -0.136 & $0.099^{d}$ & 0.217 & 0.072 & $<0.01$ \\
\hline \multicolumn{12}{|l|}{ Meat } \\
\hline Model 1: Crude & -0.020 & $0.021^{c}$ & 0.589 & $0.092^{\mathrm{a}}$ & -0.088 & $0.127^{c}$ & -0.001 & $0.094^{c}$ & -0.088 & $0.071^{c}$ & $<0.01$ \\
\hline Model 2: SES & 0.002 & $0.021^{c}$ & 0.484 & $0.093^{\mathrm{a}}$ & -0.253 & $0.130^{c}$ & -0.143 & $0.096^{c}$ & -0.152 & $0.071^{c}$ & $<0.01$ \\
\hline Model 3: Fully adjusted & 0.007 & $0.021^{c}$ & 0.469 & $0.093^{\mathrm{a}}$ & -0.297 & $0.131^{c}$ & -0.182 & $0.098^{c}$ & -0.157 & $0.071^{c}$ & $<0.01$ \\
\hline \multicolumn{12}{|l|}{ Healthy } \\
\hline Model 1: Crude & -0.085 & $0.020^{d, e, f}$ & 0.023 & $0.091^{d, e, f}$ & 0.602 & $0.125^{\mathrm{b}, \mathrm{c}}$ & 0.660 & $0.092^{\mathrm{b}, \mathrm{c}}$ & 0.415 & $0.070^{\mathrm{b}, \mathrm{c}}$ & $<0.01$ \\
\hline Model 2: SES & -0.085 & $0.021^{d, e, f}$ & 0.023 & $0.092^{\mathrm{d}, \mathrm{e}, \mathrm{f}}$ & 0.597 & $0.129^{\mathrm{b}, \mathrm{c}}$ & 0.659 & $0.095^{b, c}$ & 0.415 & $0.071^{b, c}$ & $<0.01$ \\
\hline Model 3: Fully adjusted & -0.089 & $0.021^{\mathrm{d}, \mathrm{e}, \mathrm{f}}$ & 0.033 & $0.092^{\mathrm{d}, \mathrm{e}, \mathrm{f}}$ & 0.645 & $0.130^{\mathrm{b}, \mathrm{c}}$ & 0.703 & $0.097^{\mathrm{b}, \mathrm{c}}$ & 0.414 & $0.070^{b, c}$ & $<0.01$ \\
\hline
\end{tabular}

Ethnicity was based on the country of birth of the pregnant woman and her mother including both first-generation women and second generation women. Mean, SE pattern score per dietary pattern by ethnicity.

Mean pattern scores for the total group was set to 0.000 based on PCA method.

Model 1: unadjusted.

Model 2: adjusted for SES.

Model 3: adjusted for SES, age, gender and maternal age.

Sign $(P<0.01)$ is based on ANOVA and Post-hoc Bonferroni.

${ }^{\mathrm{a}}$ sign with all groups

${ }^{\mathrm{b}}$ sign with Dutch

csign with Surinamese

${ }^{d}$ sign with Turkish

esign with Moroccan

${ }^{\mathrm{f}}$ sign with other ethnicities

SES and ethnicity in relation to pattern scores and found a borderline significant interaction for the full-fat $(p=0.018)$ and meat pattern $(p=0.017)$, whereas no interaction was present for the snacking $(p=0.324)$ and healthy $(p=0.260)$ pattern. Profile plots showed that both ethnicity and SES were independently related to dietary patterns [See Additional file 3].

\section{Discussion}

We have identified four dietary patterns in the large multi-ethnic ABCD cohort, consisting of 2769 children. Already at age 5, both ethnicity and SES were independently related to dietary patterns. Non-Dutch had high snacking and healthy pattern scores, whereas Turkish children scored higher on full-fat and Surinamese children scored higher on meat pattern scores. Low SES children had high snacking, meat and low full-fat pattern scores. Both ethnicity and SES seem to contribute independently to the differences in dietary patterns.

\section{Interpretation and comparison with previous studies}

Results of a systematic review including 14 publications utilizing PCA in 1-8 year old native children in mainly European countries [15] showed that most studies identified between two and six dietary patterns, with the majority of studies identifying a healthy, unhealthy/processed/snacking, and local/traditional pattern $[5,15,22,38]$. Among the cohorts that evaluated the diets of children aged 3-5 years, a healthy and unhealthy pattern were most often identified $[15,17,21,38-42]$ with similar dietary patterns as the healthy and snacking pattern, which were observed in the present analysis. Our full-fat pattern shows similarities with the varied traditional Norwegian pattern, found by Oellingrath in 9-10 year old Norwegian children, which was characterized by high component loadings on full-fat cheese and full-fat spreads [5], food groups that also characterized the full-fat pattern in this study.

We have identified an association between ethnicity and dietary patterns. Up to now, data on the association between ethnicity and dietary patterns has been scarce. In ALSPAC a snacking pattern was related to white 
Table 4 Mean dietary pattern scores by socioeconomic status in the ABCD cohort $(n=2769)$

\begin{tabular}{|c|c|c|c|c|c|c|c|}
\hline \multirow[t]{2}{*}{ Dietary pattern } & \multicolumn{2}{|c|}{ LOW SES } & \multicolumn{2}{|c|}{ Middle SES } & \multicolumn{2}{|c|}{ High SES } & \multirow{2}{*}{$\begin{array}{l}P \text { value } \\
\text { ANOVA }\end{array}$} \\
\hline & Mean & SE & Mean & SE & Mean & SE & \\
\hline \multicolumn{8}{|l|}{ Snacking } \\
\hline Model 1: Crude & 0.864 & $0.052^{a}$ & 0.171 & $0.030^{a}$ & -0.297 & $0.024^{a}$ & $<0.01$ \\
\hline Model 2: Ethnicity & 0.590 & $0.054^{a}$ & 0.137 & $0.029^{a}$ & -0.216 & $0.024^{a}$ & $<0.01$ \\
\hline Model 3: Fully adjusted & 0.591 & $0.054^{\mathrm{a}}$ & 0.134 & $0.029^{\mathrm{a}}$ & -0.214 & $0.024^{\mathrm{a}}$ & $<0.01$ \\
\hline \multicolumn{8}{|l|}{ Full-fat } \\
\hline Model 1: Crude & -0.179 & $0.056^{b}$ & -0.026 & 0.032 & 0.055 & $0.026^{c}$ & $<0.01$ \\
\hline Model 2: Ethnicity & -0.217 & $0.060^{b}$ & -0.028 & 0.032 & 0.065 & $0.027^{c}$ & $<0.01$ \\
\hline Model 3: Fully adjusted & -0.213 & $0.060^{\mathrm{b}}$ & -0.025 & 0.032 & 0.061 & $0.027^{c}$ & $<0.01$ \\
\hline \multicolumn{8}{|l|}{ Meat } \\
\hline Model 1: Crude & $0.229^{b}$ & 0.056 & 0.098 & $0.032^{b}$ & -0.114 & $0.026^{\mathrm{a}}$ & $<0.01$ \\
\hline Model 2: Ethnicity & 0.242 & $0.060^{b}$ & 0.096 & $0.032^{b}$ & -0.115 & $0.026^{\mathrm{a}}$ & $<0.01$ \\
\hline Model 3: Fully adjusted & 0.231 & $0.060^{\mathrm{b}}$ & 0.093 & $0.032^{b}$ & -0.111 & $0.026^{\mathrm{a}}$ & $<0.01$ \\
\hline \multicolumn{8}{|l|}{ Healthy } \\
\hline Model 1: Crude & 0.217 & $0.056^{\mathrm{a}}$ & 0.004 & $0.032^{c}$ & -0.049 & $0.026^{c}$ & $<0.01$ \\
\hline Model 2: Ethnicity & 0.025 & 0.059 & -0.019 & 0.031 & 0.008 & 0.026 & 0.716 \\
\hline Model 3: Fully adjusted & 0.043 & 0.059 & -0.019 & 0.031 & 0.003 & 0.026 & 0.618 \\
\hline
\end{tabular}

SES was based on maternal educational: low SES (<6y), middle SES (6-10y) and high SES (>10y) post-primary education.

Mean, SE pattern scores per dietary pattern by socioeconomic group.

Mean pattern scores for the total group was set to 0.000 , based on PCA method.

Model 1: unadjusted.

Model 2: adjusted for ethnicity.

Model 3: adjusted for ethnicity, age, gender and maternal age.

Sign $(P<0.01)$ is based on ANOVA and Post-hoc Bonferroni.

${ }^{\text {a sign with all groups }}$

${ }^{b}$ sign with high SES group

csign with low SES group

ethnicity at age 3 and $7[17,19]$ and a healthy pattern with non-white ethnicity at age 4 to 7 years [19]. We found both higher healthy and snacking pattern scores in non-Dutch groups. In the Netherlands, the consumption of fruit and vegetables is higher in 7-9 year old children from Turkish and Moroccan origin [43] and 9-10 year old children from non-western origin [44] than that of Dutch children. However also consumption

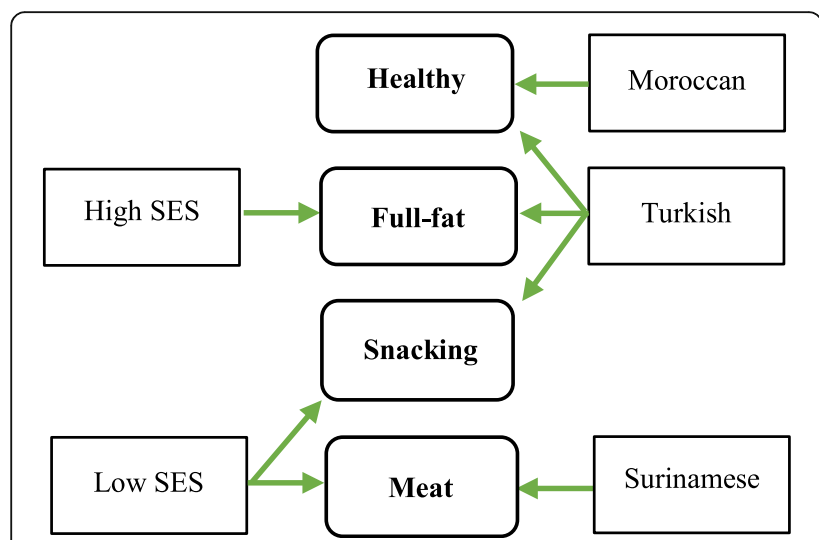

Fig. 2 The main positive significant associations between ethnicity, SES and dietary patterns $(n=2769)$ of snacking items and soft drinks has been found to be higher in 5-6y old non-ethnic groups, mainly of Turkish origin [42] which is in line with findings in our study. Additionally, the present study showed a full-fat and a meat pattern. Surinamese children have higher meat pattern scores than children from other ethnic groups and Turkish children have higher full-fat pattern scores. It has been reported in Dutch National Food Survey's that intake of fat and full-fat dairy products is high among groups from Turkish origin [25, 26].

Several studies have observed SES differences in dietary patterns in children [15-23] with maternal education being the most important variables [18, 21]. In four large prospective birth cohorts (ALSPAC, the EDEN motherchild cohort, the Norwegian Mother and Child Cohort Study and the Southampton Women's Cohort Survey) healthier dietary patterns in young children $(1-7 y)$ were associated with higher maternal education $[17,19,21$, 23, 39]. We did not find significantly different healthy pattern scores between SES groups however low SES children had higher healthy pattern scores than middle and high SES groups. In the ALSPAC cohort, the junk pattern at age 4 and 7 was more likely when maternal education level was low [20]. In line with these findings, 
we found that low SES children have higher snacking pattern scores. Our high SES children had higher full-fat pattern scores (full-fat spreads, full-fat cheese and refined pasta dishes) and low meat pattern scores (lowand high fat meat, sauces and refined grain products for warm meals). We did not find other studies describing this full-fat dietary pattern in high SES children.

In the present study, the non-Dutch groups (Surinamese, Turkish, Moroccan and other ethnicity) came disproportionally from lower SES groups (Table 1). Although ethnicity and SES are strongly correlated, we showed that both ethnicity and SES explained differences in dietary pattern scores between groups at age $5 y$. This suggests that both ethnicity and SES seem to be a predictor for adherence to a specific dietary pattern.

\section{Methodological consideration}

A problem common in studies using the PCA method is that the number of dietary patterns is based on scree plots, eigenvalues and the interpretability of the dietary patterns which is a limitation in objectivity [45]. The labelling of the identified patterns is subjective, which can be judged by the reader from the presented component loadings (Table 2). The 4 identified dietary patterns in this cohort explained $20.8 \%$ of the variation of dietary intake which is common in studies using the PCA method.

FFQs are considered an appropriate method for population-based evaluations of dietary patterns in childhood and are favoured in large-scale studies because they are less burdensome to participants and reduce postcollection processing of dietary data [27]. A possible limitation is that the FFQ was based on food commonly consumed by the Dutch population as determined by the Dutch Food Consumption Survey 1997-1998 [46]. However subanalysis showed that energy intake related to energy requirements (based on Schofield resting metabolism) was not different between Dutch and non-Dutch groups. It might be possible that some ethnic specific food items were not registered by the mother. The open question at the end of the FFQ gave the mother the opportunity to register consumed food items that were not literally asked in the 71-items. Based on methodological considerations (not all mothers filled-in this open question and there was the risk of double registration), we decided to not analyse these registered items. The FFQ was validated with the gold standard of doubly labelled water in a group of 4- to 6-year-old children, who did not exactly reflect the non-Dutch groups [29].

The present study had a response rate of $33 \%$ of the original cohort. Smaller numbers in ethnic groups is inherent to the $A B C D$ study design but it is possible that some biases may have been introduced into the analyses, particularly as the nonresponders tended to come disproportionately from lower SES and ethnic minority groups that consumed more according to the snacking pattern. Response rates per ethnic and SES group were $53 \%$ for Dutch, $23 \%$ for Surinamese, 14\% for Turkish, $15 \%$ for Moroccan, $9 \%$ for other ethnicities, $16 \%$ for low SES, 31\% for middle SES and $47 \%$ for high SES. A nonresponse analysis determining the degree of selective response and selection bias between pregnancy and birth outcomes, indicated that selective non-response was present in the ABCD-study, but selection bias was acceptably low and did not influence the studied birth outcomes [47].

Strengths of this study includes the sample size of 2769 children in which dietary pattern analyses was performed. The present study is one of few that provides insight into dietary patterns in children in a multi-ethnic population.

\section{Implications for research and interventions}

In this group of young children, we identified specific ethnic and SES groups that consumed more according to unfavourable dietary patterns. Dietary tracking, the maintenance of a dietary pattern over a certain time period, has been observed during childhood and from childhood to adolescence and unhealthy eating habits have been found to track into adolescence and adulthood.

Dietary habits are a major determinant of overweight $[4,5]$. Non-native, especially children of Turkish origin, and low SES groups show higher adherence to the unfavourable snacking pattern and show disproportionally higher prevalence of overweight and obesity (7\% for Dutch, $14 \%$ for Surinamese, 25\% for Turkish, 23\% for Moroccan, $17 \%$ for low SES, $12 \%$ for middle SES and $8 \%$ for high SES) at age 5 [48]. Future studies could analyse the explanatory factors in early childhood contributing to these (differences in) dietary choices and the possible relationships these dietary patterns may have with weight development and health inequalities in later childhood.

\section{Conclusion}

This study indicates that both ethnicity and SES are relevant for dietary patterns at age 5 and may enable more specific nutrition education to specific ethnic and low SES target groups, in order to avoid overweight and other health inequalities.

\section{Additional files}

Additional file 1: Food groups and their products, used in the PCA analysis in the ABCD cohort ( $n=2$ 769). (PDF $23 \mathrm{~kb}$ )

Additional file 2: Scree plot of the 41 components in the PCA in the ABCD cohort ( $n=2$ 769). (PDF $36 \mathrm{~kb}$ )

Additional file 3: Profile plots of the interaction between ethicity and SES per dietary pattern ( $n=2$ 769). (PDF $92 \mathrm{~kb}$ ) 


\section{Abbreviations}

ABCD: Amsterdam Born Children and their Development;

SES: socioeconomic status; ANOVA: Analysis of Variance; ALSPAC: The Avon Longitudinal Study of Parents and Children; FFQ: Food Frequency Questionnaire; PCA: Principal Component Analysis

\section{Acknowledgements}

This work would not have been possible without the participants and the youth health care centers in Amsterdam, the Netherlands.

\section{Funding}

This work was supported by the Netherlands Organisation for Scientific Research (NWO) (V.R., grant number 023.002.105); The ABCD-study was supported by the Academic Medical Centre (AMC) in Amsterdam, The Netherlands and the Public Health Service (GGD) in Amsterdam, The Netherlands.

\section{Availability of data and materials}

Data are not publically available due to ethical restrictions related to protecting patient confidentiality. The datasets analysed during the current study are available from the corresponding author on reasonable request

\section{Authors' contributions}

$V R, M v E$, PJMW, APV, formulating the research questions and designing the study; VR, MvE, MFE, LHD analysing the data; VR, MFE, MvE, MN, LHD, PJMW APV, writing the article; and VR, MFE, PJMW had primary responsibility for final content. All authors read and approved the final manuscript.

\section{Ethics approval and consent to participate}

All participants gave written informed consent for themselves and their children.

This study was conducted according to the guidelines of the Declaration of Helsinki and all procedures were approved by the Central Committee on Research Involving Human Subjects, the Medical Research Ethics Committees of the participating hospitals, and the Registration Committee of the municipality of Amsterdam.

\section{Competing interest}

The authors declare they have no competing interests.

\section{Consent for publication}

Not applicable.

\section{Publisher's Note}

Springer Nature remains neutral with regard to jurisdictional claims in published maps and institutional affiliations.

\section{Author details \\ ${ }^{1}$ Department of Nutrition and Dietetics, Faculty of Sports and Nutrition, Amsterdam University of Applied Sciences, Dr. Meurerlaan 8, 1067, SM, Amsterdam, The Netherlands. ${ }^{2}$ Department of Epidemiology, Health Amsterdam, The Netherlands. ${ }^{3}$ Department of Public Health, Academic The Netherlands. ${ }^{4}$ Department of Sociology, University of Amsterdam, Amsterdam, The Netherlands. ${ }^{5}$ Nutrition and Dietetics, Department of Internal Medicine, VU University Medical Center, Amsterdam, The Netherlands. \\ Received: 2 June 2017 Accepted: 20 December 2017 \\ Published online: 08 January 2018} Promotion and Health Care Innovation, Public Health Service Amsterdam, Medical Center, University of Amsterdam, Amsterdam Public Health Institute,

\section{References}

1. CBS Population statistics 2014. http://statline.cbs.nl/StatWeb/publication/ $? \mathrm{~W}=\mathrm{T} \& D M=S L N L \& P A=37296$ ned $\& D 1=a \& D 2=0,10,20,30,40,50,60, \% 281-$ 1\%29, I\&HD=130605-0924\&HDR=G1\&STB=T. Accessed July 12015.

2. van Dommelen $P$, Schönbeck $Y$, HiraSing RA, van Buuren S. Call for early prevention: prevalence rates of overweight among Turkish and Moroccan children in the Netherlands. Eur J Pub Health. 2015;25:828-33.

3. de Hoog ML, van Eijsden M, Stronks K, Gemke RJ, Vrijkotte TG. Overweight at age two years in a multi-ethnic cohort ( $A B C D$ study): the role of prenatal factors, birth outcomes and postnatal factors. BMC Public Health. 2011;11:611.

4. Branca F, Nikogosian $\mathrm{H}$, Lobstein $\mathrm{T}$. The challenge of obesity in the WHO European region and the strategies for response. 2007. http://www.euro. who.int/_data/assets/pdf_file/0010/74746/E90711.pdf. Accessed July 12015.

5. Oellingrath $\mathrm{IM}$, Svendsen MV, Brantsaeter AL. Eating patterns and overweight in 9- to 10-year-old children in Telemark County, Norway: a cross-sectional study. Eur J Clin Nutr. 2010;64(11):1272-9.

6. Brug J, van Stralen MM, Chinapaw MJ, De Bourdeaudhuij I, Lien N, Bere E, Singh AS, Maes L, Moreno L, Jan N, Kovacs E, Lobstein T, Manios Y, Te Velde $S J$. Differences in weight status and energy-balance related behaviours according to ethnic background among adolescents in seven countries in Europe: the ENERGY-project. Pediatr Obes. 2012;7(5):399-411.

7. Dietary HFB. Pattern analysis: a new direction in nutritional epidemiology. Curr Opin Lipidol. 2002;13(1):3-9.

8. Newby PK, Tucker KL. Empirically derived eating patterns using factor or cluster analysis: a review. Nutr Rev. 2004;62(5):177-203.

9. Jacques PF, Tucker KL. Are dietary patterns useful for understanding the role of diet in chronic disease? Am J Clin Nutr. 2001;73(1):1-2

10. Balder HF, Virtanen M, Brants HA, Krogh V, Dixon LB, Tan F, Mannisto S, Bellocco R, Pietinen P, Wolk A, Berrino F, Van den Brandt PA, Hartman AM, Goldbohm RA. Common and country-specific dietary patterns in four European cohort studies. J Nutr. 2003;133(12):4246-51.

11. Béghin L, Dauchet L, De Vriendt T, Cuenca-García M, Manios Y, Toti E, Plada M, Widhalm K, Repasy J, Huybrechts I, Kersting M, Moreno LA, Dallongeville J, HELENA Study Group. Influence of parental socio-economic status on diet quality of European adolescents: results from the HELENA study. Br J Nutr. 2014;111(7):1303-12.

12. SCP. The Netherlands Institute for Social Research. https://www.scp.nl/ Publicaties/Alle_publicaties/Publicaties_2008/Minderheden_meer_gewicht. Accessed 18 Jan 2018.

13. Eurostat Migration and migrant population statistics. 2016. http://ec.europa. eu/eurostat/statistics-explained/index.php/Migration_and_migrant population_statistics. Accessed 5 Jan 2018.

14. Eurostat Migrant integration statistics - education 2016. http://ec.europa.eu/ eurostat/statistics-explained/index.php/Migrant_integration_statistics_education. Accessed March 42016.

15. Smithers LG, Golley RK, Brazionis L, Lynch JW. Characterizing whole diets of young children from developed countries and the association between diet and health: a systematic review. Nutr Rev. 2011;69(8):449-67.

16. Leech RM, McNaughton SA, Timperio A. The clustering of diet, physical activity and sedentary behavior in children and adolescents: a review. Int J Behav Nutr Phys Act. 2014;22;11:4.

17. North K, Emmett P. Multivariate analysis of diet among three-year-old children and associations with socio-demographic characteristics. The Avon longitudinal study of pregnancy and childhood (ALSPAC) study team. Eur J Clin Nutr. 2000;54(1):73-80

18. Northstone $K$, Emmett $P$. The associations between feeding difficulties and behaviours and dietary patterns at 2 years of age: the ALSPAC cohort. Matern Child Nutr. 2013:9(4):533-42.

19. Northstone K, Emmett P. Multivariate analysis of diet in children at four and seven years of age and associations with socio-demographic characteristics. Eur J Clin Nutr. 2005;59(6):751-60.

20. Camara S, De Lauzon-Guillain B, Heude B, Charles MA, Botton J, Plancoulaine S, Forhan A, Saurel-Cubizolles MJ, Dargent-Molina P, Lioret S. On behalf the EDEN mother-child cohort study group. Multidimensionality of the relationship between social status and dietary patterns in early childhood: Iongitudinal results from the French EDEN mother-child cohort. Int J Behav Nutr Phys Act. 2015;12:122.

21. Lioret S, Betoko A, Forhan A, Charles MA, Heude B, De Lauzon-Guillain B. EDEN mother-child cohort study group.. Dietary patterns track from infancy to preschool age: cross-sectional and longitudinal perspectives. J Nutr. 2015:145(4):775-82.

22. Kristiansen AL, Lande B, Sexton JA, Andersen LF. Dietary patterns among Norwegian 2-year-olds in 1999 and in 2007 and associations with child and parent characteristics. Br J Nutr. 2013;110(1):135-44.

23. Robinson S, Marriott L, Poole J, Crozier S, Borland S, Lawrence W, Law C, Godfrey K, Cooper C, Inskip H. Southampton Women's survey study group. Dietary patterns in infancy: the importance of maternal and family influences on feeding practice. Br J Nutr. 2007;98(5):1029-37. 
24. Brussaard JH, Brandts HAM, van Erp-Baart AMJ. Dutch Food Consumption Survey. 1999. TNO-rapport nr. V99.1099. Zeist: TNO.

25. de Boer EJ, Brants HAM, Beukers M, Ocke MC, Dekker L, Nicolaou M, Snijder M. Voeding van Marokkaanse, Turkse, Surinaamse, en autochtone Nederlanders in Amsterdam. National Institute for Public Health and the Environment (RIVM). 2015. RIVM rapport 2015-0099. http://www.rivm.nl/ dsresource?objectid=a809a52f-e8c0-42d5-af89-aedd5b63713c\&type= org\&disposition=inline. Accessed January 252016.

26. Dekker LH, Nicolaou M, van Dam RM, de Vries JH, de Boer EJ, Brants HA, Beukers MH, Snijder MB, Stronks K. Socio-economic status and ethnicity are independently associated with dietary patterns: the HELIUS-dietary patterns study. Food Nutr Res. 2015;59:26317.

27. Hiza HA, Casavale KO, Guenther PM, Davis CA. Diet quality of Americans differs by age, sex, race/ethnicity, income, and education level. J Acad Nutr Diet. 2013;113(2):297-306.

28. van Eijsden M, Vrijkotte TG, Gemke RJ, van der Wal MF. Cohort profile: the Amsterdam born children and their development (ABCD) study. Int J Epidemiol. 2011;40(5):1176-86.

29. Dutman AE, Stafleu A, Kruizinga A, Brants HA, Westerterp KR, Kistemaker C, Meuling WJ, Goldbohm RA. Validation of an FFQ and options for data processing using the doubly labelled water method in children. Public Health Nutr. 2011;14(3):410-7.

30. National Institute for Public Health and the Environment. NEVO-online version 2010/2.0. Bilthoven: RIVM. 2010. http://www.rivm.nl/Onderwerpen/ N/Nederlands_Voedingsstoffenbestand

31. de Wilde JA, van Dommelen P, Middelkoop BJ. Appropriate body mass index cut-offs to determine thinness, overweight and obesity in south Asian children in the Netherlands. PLoS One. 2013;8(12):e82822.

32. Stronks K, Kulu-Glasgow I, Agyemang C. The utility of 'country of birth' for the classification of ethnic groups in health research: the Dutch experience. Ethn Health. 2009;14(3):255-69.

33. Van Den Berg G, Van Eijsden M, Galindo-Garre F, Vrijkotte T, Gemke R. Low maternal education is associated with increased growth velocity in the first year of life and in early childhood: the ABCD study. Eur J Pediatr. 2013;172(11):1451-7.

34. Willett WC, Howe GR, Kushi LH. Adjustment for total energy intake in epidemiologic studies. Am J Clin Nutr. 1997;65:1220S-8S.

35. Northstone K, Ness AR, Emmett PM, Rogers IS. Adjusting for energy intake in dietary pattern investigations using principal components analysis. Eur J Clin Nutr. 2008;62(7):931-8.

36. Cattell RB. The scree test for the number of factors. Multivariate Behav Res. 1966;1:245-76.

37. Kline P. An easy guide to factor analysis. London: Routledge; 1994

38. Pryer JA, Rogers S. Dietary patterns among a national sample of British children aged 1 1/2-4 1/2 years. Public Health Nutr. 2009;12:957-66.

39. Ystrom E, Barker M, Vollrath ME. Impact of mothers' negative affectivity, parental locus of control and child-feeding practices on dietary patterns of 3-year-old children: the MoBa cohort study. Matern Child Nutr. 2012;8:103-14

40. Friedman LS, Lukyanova EM, Serdiuk A, Shkiryak-Nizhnyk ZA, Chislovska NV, Zvinchuk AV, Oliynyk I, Hryhorczuk D. Social-environmental factors associated with elevated body mass index in a Ukrainian cohort of children. Int J Pediatr Obes. 2009;4(2):81-90.

41. Shin KO, SY O, Park HS. Empirically derived major dietary patterns and their associations with overweight in Korean preschool children. Br J Nutr. 2007;98(2):416-21.

42. Kuepper-Nybelen J, Lamerz A, Bruning N, Hebebrand J, Herpertz-Dahlmann $\mathrm{B}$, Brenner H. Major Differences in prevalence of overweight according to nationality in preschool children living in Germany: determinants and public health implications. Arch Dis Child. 2005;90(4):359-63.

43. RIVM The National Public Health Compass 2013. http://www. nationaalkompas.nl/gezondheidsdeterminanten/leefstij/voeding/zijn-erverschillen-naar-etniciteit/ Accessed January 252016

44. Tak NI, Te Velde SJ, Brug J. Ethnic differences in 1-year follow-up effect of the Dutch Schoolgruiten project - promoting fruit and vegetable consumption among primary-school children. Public Health Nutr. 2007;10:1497-507.

45. Oellingrath IM, Svendsen MV, Brantsaeter AL. Tracking of eating patterns and overweight - a follow-up study of Norwegian schoolchildren from middle childhood to early adolescence. Nutr J. 2011;10:106.

46. Anon. Zo eet Nederland, 1998. Food consumption survey 1997-1998. Den Haag: Voedingscentrum 1998.
47. Tromp M, van Eijsden M, Ravelli AC, Bonsel GJ. Anonymous non-response analysis in the ABCD cohort study enabled by probabilistic record linkage. Paediatr Perinat Epidemiol. 2009;23(3):264-72.

48. Outcome Monitor Amsterdamse Aanpak gezond Gewicht. Staat van gezond gewicht en leeftijl van Amsterdamse kinderen. Amsterdam Municipality (2017). https://jongerenopgezondgewicht.nl/userfiles/Meten/outcome_ monitor_aanpak_gezond_gewicht_2017.pdf. Accessed March 102017.

\section{Submit your next manuscript to BioMed Central and we will help you at every step:}

- We accept pre-submission inquiries

- Our selector tool helps you to find the most relevant journal

- We provide round the clock customer support

- Convenient online submission

- Thorough peer review

- Inclusion in PubMed and all major indexing services

- Maximum visibility for your research

Submit your manuscript at www.biomedcentral.com/submit
Biomed Central 